\title{
Intracerebral hemorrhage: toward physiological imaging of hemorrhage risk in acute and chronic bleeding
}

\section{Raphael Jakubovic* and Richard I. Aviv}

Department of Medical Imaging, Sunnybrook Health Sciences Centre, Sunnybrook Health Sciences Centre, Toronto, ON, Canada

Edited by:

Steven M. Greenberg, Harvard, USA

Reviewed by:

Edward Feldmann, Brown University USA

Stefano Ricci, Ospedale, Italy

*Correspondence:

Raphael Jakubovic, Division of

Neuroradiology, Room AG 31e,

Sunnybrook Health Sciences Centre,

2075 Bayview Avenue, Toronto, ON,

Canada M4N 3 M5.

e-mail: raphael.jakubovic@

sunnybrook.ca
Despite improvements in management and prevention of intracerebral hemorrhage (ICH), there has been little improvement in mortality over the last 30 years. Hematoma expansion, primarily during the first few hours is highly predictive of neurological deterioration, poor functional outcome, and mortality. For each $10 \%$ increase in $\mathrm{ICH}$ size, there is a $5 \%$ increase in mortality and an additional $16 \%$ chance of poorer functional outcome. As such, both the identification and prevention of hematoma expansion are attractive therapeutic targets in $\mathrm{ICH}$. Previous studies suggest that contrast extravasation seen on CT Angiography (CTA), MRI, and digital subtraction angiography correlates with hematoma growth, indicating ongoing bleeding. Contrast extravasation on the arterial phase of a CTA has been coined the CTA Spot Sign. These easily identifiable foci of contrast enhancement have been identified as independent predictors of hematoma growth, mortality, and clinical outcome in primary $\mathrm{ICH}$. The Spot Sign score, developed to stratify risk of hematoma expansion, has shown high inter-observer agreement. Post-contrast leakage or delayed CTA Spot Sign, on post contrast CT following CTA or delayed CTA respectively are seen in an additional $\sim 8 \%$ of patients and explain apparently false negative observations on early CTA imaging in patients subsequently undergoing hematoma expansion. CT perfusion provides an opportunity to acquire dynamic imaging and has been shown to quantify rates of contrast extravasation. Intravenous recombinant factor $\mathrm{VIla}$ ( $\mathrm{rFVIIa}$ ) within $4 \mathrm{~h}$ of $\mathrm{ICH}$ onset has been shown to significantly reduce hematoma growth. However, clinical efficacy has yet to be proven. There is compelling evidence that cerebral amyloid angiopathy (CAA) may precede the radiographic evidence of vascular disease and as such contribute to microbleeding. The interplay between microbleeding, CAA, CTA Spot Sign and genetic composition (ApoE genotype) may be crucial in developing a risk model for $\mathrm{ICH}$.

Keywords: intracerebral hemorrhage, computed tomography angiography, contrast extravasation, CTA spot sign, cerebral amyloid angiopathy

\section{INTRODUCTION}

Intracerebral hemorrhage (ICH) accounts for $10-15 \%$ of all stroke events (Qureshi et al., 2001). Despite vast improvements in stroke management and prevention, there has been little improvement in the prevalence and mortality of ICH over the last 30 years (Lovelock et al., 2007). In-hospital rates of mortality and patient disability following ICH are 40 and $80 \%$ respectively (van Asch et al., 2010) and the 1 month mortality rate is $30-50 \%$ (Broderick et al., 1999; Nilsson et al., 2002). In approximately half of ICH cases which ultimately prove fatal, death occurs within $48 \mathrm{~h}$ of symptom onset (Broderick et al., 1999; Nilsson et al., 2002). The impact of disability is also far-reaching. The vast majority of patients who survive the ICH ictus do not regain their independence within 6 months of symptom onset. At 6 months only $20 \%$ achieve independence in their daily lives (Broderick et al., 1999).

Hemorrhages are generally categorized as primary or secondary. ICH is considered primary in $78-88 \%$ of cases often attributed to hypertensive vasculopathy and cerebral amyloid angiopathy (CAA; Broderick et al., 1999). CAA is seen in 40-60\% of patients older than 70 (Gilbert and Vinters, 1983; Vinters and Gilbert, 1983), and is considered responsible for the majority of primary lobar ICH occurring in the elderly population (Gilbert and Vinters, 1983; Vinters and Gilbert, 1983; O'Donnell et al., 2000; Walker et al., 2004). Secondary ICH can be caused by arteriovenous malformations (AVMs), ruptured aneurysms, anticoagulation, hemorrhage into neoplasm, and infarction (Mayer, 2005). As the population ages, the rates of $\mathrm{ICH}$ are expected to rise, largely due to increased incidence of CAA, high prevalence of hypertension, and the widespread use of anticoagulants (Flaherty et al., 2007; Mayo et al., 2007). Recent studies in the United States have shown an $18 \%$ increase in hospital admission for ICH over the last 10 years (Qureshi et al., 2007). As such, detection and management of ICH are particularly important in reducing rates of mortality and disability attributed to hemorrhage.

\section{SIZE OF HEMATOMA AND HEMATOMA EXPANSION}

Hematoma size in ICH is an important prognostic indicator of the extent of tissue damage, neurological deficit and functional outcome. ICH volume is a powerful predictor of 30 day mortality (Broderick et al., 1993). In many instances ICH patients present with modest deficits, indicative of a smaller hematoma size, followed by a rapid clinical deterioration secondary to ongoing 
bleeding and hematoma expansion (Kazui et al., 1996; Leira et al., 2004). Hematoma expansion occurs in up to $40 \%$ of ICH (Brott et al., 1997; Fujii et al., 1998), usually manifesting within the first few hours and is highly predictive of neurological deterioration, poor functional outcome, and mortality (Broderick et al., 1993; Kazui et al., 1996, 1997; Leira et al., 2004). For each 10\% increase in $\mathrm{ICH}$ size, there is a $5 \%$ increase in mortality and $16 \%$ increase in the probability of poorer functional outcome (Davis et al., 2006). Hematoma growth is considered a hyperacute phenomenon. Expansion generally occurs primarily within $3 \mathrm{~h}$ of symptom onset, but can manifest up to $12 \mathrm{~h}$ post ICH ictus (Kazui et al., 1996; Brott et al., 1997; Fujii et al., 1998; Qureshi et al., 2006). This time dependence is highly sensitive and significant ICH growth ( $>33 \%$ volume increase from baseline) occurs in $18-38 \%$ of patients scanned within $3 \mathrm{~h}$ of symptom onset (Kazui et al., 1996; Brott et al., 1997; Fujii et al., 1998; Flaherty et al., 2006) and 8-16\% scanned within 3-6h (Kazui et al., 1996; Cheung, 1998; Fujii et al., 1998). A recent report indicated that any absolute growth predicts poor clinical outcome; an increase of only $3 \mathrm{~mL}$ has a positive predictive value of $70 \%$ for death or major disability (Dowlatshahi et al., 2011). The pathological evolution of hematoma growth has not been characterized, but may be attributed to continuous bleeding or rebleeding of the initial hemorrhage (Fisher, 1971). Dowlatshahi et al. (2011) recently showed that any measure of hematoma expansion independently predicted poor outcome. As such, both the identification and prevention of hematoma expansion is of significant importance in the treatment of ICH. Successful prevention of hematoma growth is long considered the goal of ICH management. Theoretically, by limiting the extent of the hematoma, through effective management and intervention it may be possible to reduce mortality rates and improve functional outcomes.

\section{BLOOD PRESSURE MANAGEMENT}

Blood pressure control following acute $\mathrm{ICH}$ has been shown to reduce the risk of hematoma expansion (Fogelholm et al., 1997; Ohwaki et al., 2004). Lowering blood pressure in an acute phase should limit hematoma growth and result in better functional outcomes. American Heart Association (AHA) guidelines for the management of ICH recommend treatment with antihypertensive agents for patients with mean arterial pressure greater than $130 \mathrm{mmHg}$ (Broderick et al., 1999). In order to reduce the risk of further tissue damage attributed to hypotension, cerebral blood pressure should be maintained above $70 \mathrm{~mm} \mathrm{Hg}$ (Broderick et al., 1999). A recent study demonstrated that early aggressive blood pressure management in acute $\mathrm{ICH}$ reduced hematoma growth within $6 \mathrm{~h}$ of ICH onset (Anderson et al., 2008). An aggressive approach relative to standard clinical care based on AHA guidelines (target: SBP $<140 \mathrm{~mm} \mathrm{Hg}$ vs. SBP $<180 \mathrm{~mm} \mathrm{Hg}$ ) resulted in a $22.6 \%$ reduction in hematoma size (Anderson et al., 2008). Thus, effective management of blood pressure particularly in a hyperacute phase is an imperative, irrespective of imaging surrogates.

\section{IMAGING OF INTRACEREBRAL HEMORRHAGES}

Since ICH growth is considered to be time dependant, early identification of ICH is crucial. Although clinical symptoms may suggest
ICH, confirmation can only be obtaining through CT or MR imaging. A non-contrast CT (NCCT) is considered the gold standard for identification of acute $\mathrm{ICH}$, while $\mathrm{T} 2 *$ susceptibility weight $\mathrm{MR}$ is superior at detecting remote hemorrhage (Fiebach et al., 2004; Chalela et al., 2007). MR imaging can provide information regarding the time of hemorrhage, degree of perihematomal edema, cerebral microbleeds, and cavernomas (Morgenstern et al., 2010). American Heart Association/American Stroke Association (AHA/ASA) guidelines indicate that both NCCT and MR images are appropriate in diagnosing $\mathrm{ICH}$, however due to the wide availability, low cost, and rapid scan times, NCCT is widely used (Broderick et al., 1999, 2007; Morgenstern et al., 2010).

The 2007 AHA/ASA guidelines recommended digital subtraction angiography (DSA) or CT angiography (CTA) for all patients without a clear cause for hemorrhage, who are surgical candidates (Broderick et al., 1999). Other emphasized indications for angiography include: the presence of subarachnoid hemorrhage, abnormal calcifications, and patients with isolated intraventricular hemorrhage (IVH; Broderick et al., 2007). The guidelines indicated that DSA is not required in older hypertensive patients with so-called typical hypertensive bleeds within the basal ganglia, thalamus, cerebellum, or brainstem unless the NCCT findings are suspicious for an underlying lesion. The most recent AHA/ASA guidelines recommend neuroimaging with $\mathrm{CT}$ or MRI in order to distinguish ischemic from hemorrhagic stroke, in addition to CTA and contrast enhanced CT (CECT) to assess risk of hematoma expansion (Morgenstern et al., 2010). When secondary ICH is suspected, CT venography, CECT, contrast enhanced MR, and $\mathrm{MR}$ angiography/venography can be used to diagnosis underlying lesions (Morgenstern et al., 2010).

\section{CONTRAST EXTRAVASATION}

Early vascular imaging may be beneficial in identifying surrogates for active bleeding and hematoma expansion. One particular surrogate for identifying ongoing bleeding is contrast extravasation. Previous studies suggest that contrast extravasation seen on CTA, MRI, and DSA, in patients with ICH correlates with hematoma growth and indicates active bleeding (Kowada et al., 1972; Yamaki et al., 1983; Kobayashi et al., 1985; Komiyama et al., 1995; Becker et al., 1999). Wada et al. (2007) showed contrast extravasation to be an independent indicator of hematoma growth. Goldstein et al. (2007) found contrast extravasation in $56 \%$ of patients and the single most powerful predictor of ICH expansion (sensitivity $94 \%$, specificity 50\%, NPV 98\%). Kim et al. demonstrated contrast extravasation independently predicts ICH growth and mortality: 30 -day mortality was $53 \%$ in those with extravasation vs. $19.5 \%$ without (Aviv et al., 2008; Kim et al., 2008). The identification of contrast extravasation can potentially serve as an acute surrogate marker of poor outcome, and aid in the treatment process.

\section{CTA SPOT SIGN}

Contrast extravasation on the arterial phase of a CTA has been coined the CTA Spot Sign. The Spot Sign was initially proposed in 2007 as an indicator of hematoma expansion (Goldstein et al., 2007; Wada et al., 2007). Described as tiny foci of enhancement seen on CTA of spontaneous ICH, the Spot Sign is highly predictive of hematoma expansion (Goldstein et al., 2007; Wada et al., 
2007; Kim et al., 2008; Delgado Almandoz et al., 2009; Hallevi et al., 2010), mortality and clinical outcome (Kim et al., 2008; Delgado Almandoz et al., 2009; Hallevi et al., 2010) (Figure 1). Enhancement is thought to represent extra-luminal extravasation and may appear serpiginous to spot-like, single or multiple and demonstrate a density approximately double that of the surrounding hematoma (Thompson et al., 2009; Li et al., 2011). To differentiate from secondary vascular malformations, extravasation should occur within the hematoma without identifiable external vessel connection (Figure 2). The radiographic definition of a Spot Sign, different morphological patterns, and potential mimics are now well documented (Gazzola et al., 2008; Thompson et al., 2009). Figure 3 demonstrates a Spot Sign with contrast extravasation which resulted in hematoma expansion. These contrast-enhancing foci are of uncertain etiology but are postulated to represent pseudoaneurysms, Charcot-Bouchard aneurysms (Charcot and Bouchard, 1868), fibrin globes or a focal vessel defect in an abnormal vessel segment (Fisher, 1971). Irrespective of the pathophysiology, the Spot Sign is regarded as a potent radiological marker of acute primary, or possibly secondary, vessel damage.

The first study to describe the Spot Sign, demonstrated a prevalence of $33 \%$. The presence of the Spot Sign served as a predictor of ICH growth, defined as an increase in size of more than $30 \%$ of the initial volume or an absolute increase of $6 \mathrm{ml}$ (sensitivity $91 \%$, specificity $89 \%$, PPV 77\%, NPV 96\%). ICH expansion was found to be more common in patients presenting with a Spot Sign, and the Spot Sign was shown to independently predict ICH expansion. Functional outcomes were worse in patients presenting with the Spot Sign than those without. Death or severe disability occurred more often in patients with the Spot Sign, than those without (50 vs. $35 \%)$. Recently, a large study ( $n=367$ ) has provided strong validation of the Spot Sign (Delgado Almandoz et al., 2009, 2010). The positive predictive value (PPV) for significant ICH growth was highest for a Spot Sign with greater than or equal to three spots (PPV 96\%), axial dimension greater than $5 \mathrm{~mm}$ (PPV 91\%), and attenuation greater than 180 hounsfield units (HU; PPV 84\%). Recent findings of the multi-centered PREDICT study confirmed the Spot Sign as a predictor of hematoma expansion in acute ICH (Demchuk et al., 2012). The Spot Sign score, based on number of Spot Signs, size of ICH, and attenuation of signal, was specifically

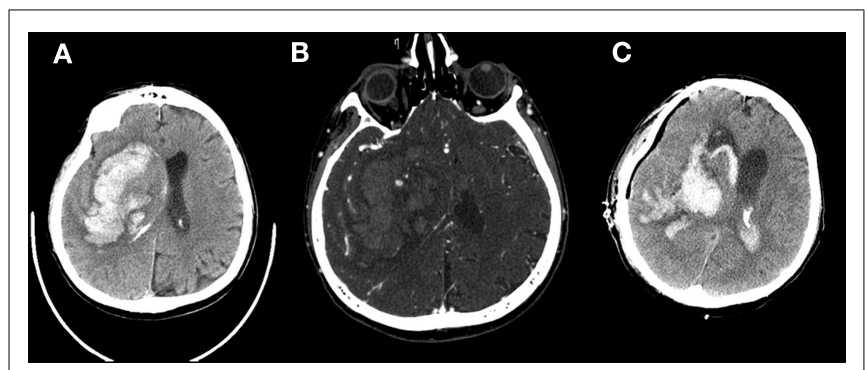

FIGURE 1 | A 61-year old male patient presenting within $80 \mathrm{~min}$ of symptom onset. (A) Axial non-contrast $\mathrm{CT}$ demonstrates massive intraparenchymal hemorrhage projected over the basal ganglia with severe mass effect and ipsilateral ventricular hemorrhage. (B) Multiple Spot Signs were present on CTA raw images. (C) Patient underwent emergent craniectomy and hematoma evacuation demonstrated 1 day later. developed to stratify risk of hematoma expansion, and ultimately mortality, in patients with ICH. The calculation is based on (1) number of Spot Signs ( $1-2$ spots $=1$ point, $\geq 3$ spots $=2$ points $)$, (2) maximum axial dimension ( $1-4 \mathrm{~mm}=0$ points, $\geq 5 \mathrm{~mm}=1$ point), and (3) maximum attenuation $(120-179 \mathrm{HU}=0$ points, $\geq 180 \mathrm{HU}=1$ point), for a maximum of 4 points. The Spot Sign score was able to predict significant ICH growth independent of ICH volume, blood pressure, INR, and time from onset to scan. Mean ICH growth for patient with Spot Sign scores of 3 or 4 was 21-36 vs. $11 \mathrm{~mL}$ for Spot Sign negative patients. Most notably, inter-observer agreement for identification of the Spot Sign score was excellent $(k=0.88-0.93)$. While the Spot Sign score can be rapidly performed and does predict hematoma expansion reasonably well, it is suboptimal for predicting in-hospital mortality (sensitivity $41 \%$, specificity $85 \%$, PPV $56 \%$, NPV $76 \%$, Acc $71 \%$ ) and poor functional outcome 3 month post ICH ictus (sensitivity $23 \%$, specificity $89 \%$, PPV $51 \%$, NPV $70 \%$, Acc $67 \%$ ) due to poor sensitivity and accuracy.

A crucial factor in the assessment of Spot Sign and contrast extravasation presence is the timing of the CTA acquisition. Additional regions of contrast accumulation, not detected by the initial CTA acquisition, and independent of the Spot Sign, may still be present (Wada et al., 2007; Delgado Almandoz et al., 2009; Ederies et al., 2009). These addition sites of contrast extravasation, visible on a post-contrast CT, performed minutes after the CTA or a delayed CTA, are referred to as post-contrast leakage (PCL) or delayed CTA Spot Sign respectively (Figure 4). Approximately 8\% of purportedly Spot Sign negative ICH that undergo hematoma expansion (Delgado Almandoz et al., 2009; Ederies et al., 2009) harbor PCL which increases the sensitivity for hematoma expansion by $16 \%$ (Ederies et al., 2009). Figure 5 demonstrates a Spot Sign positive hematoma that does not contain PCL. The inclusion of a post-contrast CT or delayed CTA into the ICH protocol may allow for a more robust Spot Sign score and allow for better stratification of the risk and rates hematoma expansion. However, better strategies are now available including dynamic Spot evaluation.

\section{DYNAMIC CT IMAGING AND A DYNAMIC SPOT SIGN}

Dynamic CT imaging provides an alternative to the use of a postcontrast CT or a delayed CTA by allowing real time assessment

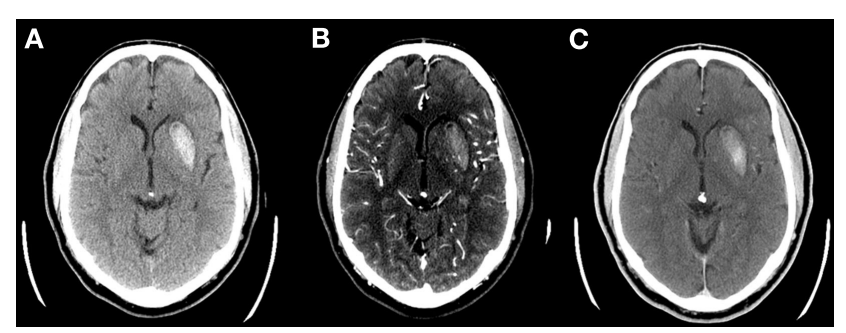

FIGURE 2 |A 61-year old male patient presenting within $60 \mathrm{~min}$ of symptom onset. (A) Unenhanced CT demonstrates acute putamen hemorrhage. (B) CT angiography demonstrates a Spot Sign with contrast extravasation. The contrast density was not continuous with the lenticulostriate vessels seen displaced posteromedial to the hematoma. (C) Post-contrast CT demonstrates contrast accumulation posteriorly within the hematoma consistent with extravasation. 


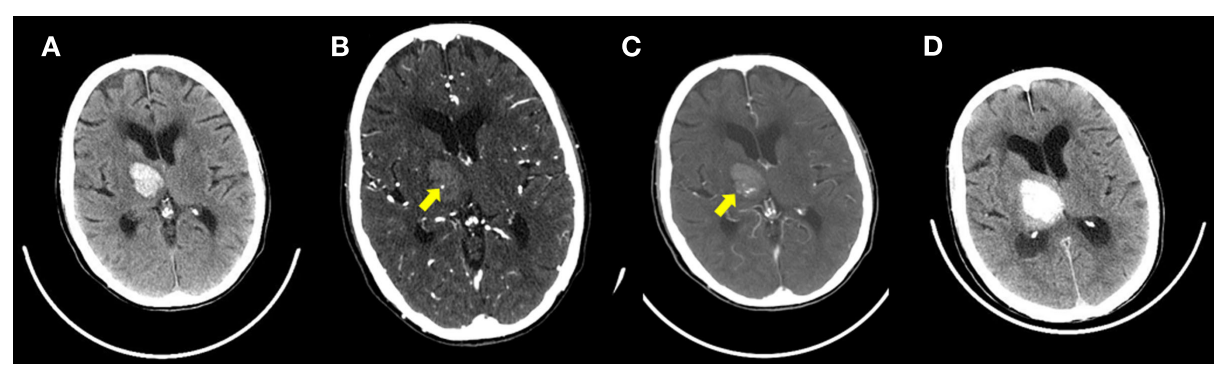

FIGURE 3 | A 86 year old female patient presenting within 90 min of symptom onset. (A) Unenhanced CT demonstrates right thalamic and internal capsule hematoma with associated third ventricle mass effect. (B) A small focus of enhancement consistent with the Spot Sign is seen on the CTA raw image. (C) Post-contrast CT performed immediately following the CTA shows increase in contrast density from the CTA consistent with active contrast extravasation. (D) Unenhanced follow up CT at $6 \mathrm{~h}$ demonstrates early hematoma expansion. A trace of intraventricular hemorrhage is present within the right trigone.

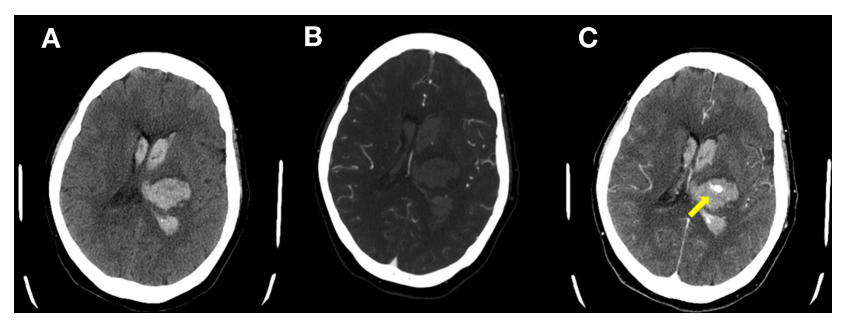

FIGURE 4 | A 63 year old female patient presenting within $100 \mathrm{~min}$ of symptom onset. (A) Axial non-contrast CT demonstrates acute hematoma in the left thalamus and intraventricular blood. (B) No Spot Sign was present on CTA source images. (C) Post-contrast leakage was demonstrated on the post-contrast CT image.

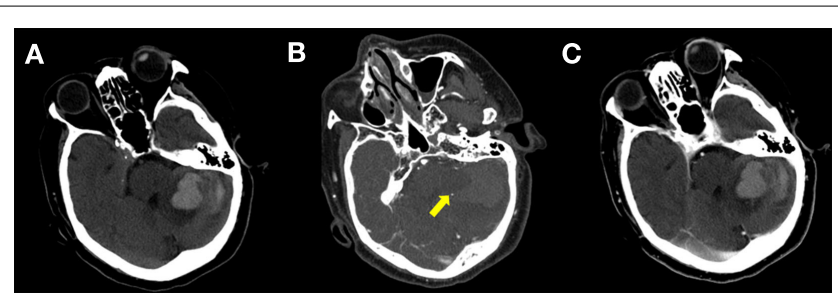

FIGURE 5 | A 65 year old female patient presenting within $3 \mathrm{~h}$ of symptom onset. (A) Axial non-contrast CT demonstrates acute hematoma in the left cerebellum. (B) Spot Sign is present at the margin of hematoma. (C) Post-contrast CT demonstrates no evidence of extravasation or post-contrast leakage.

of contrast extravasation. Conventional CT imaging is limited by lower spatial coverage compared to 320 slice scanners. These newer scanners can rapidly acquire the entire brain allowing for multiple whole head acquisitions. The acquisitions may be reconstructed to provide simultaneous CTA and CTP data. Acquiring dynamic images demonstrate the evolution of contrast extravasation, including Spot Sign presence and post-contrast leakage. A single report using dynamic CTA identified delayed contrast extravasation in a purportedly CTA Spot Sign negative hemorrhage (Chakraborty et al., 2010). Disadvantages of such acquisitions include increased radiation dose and the large amount of raw data acquired.

CT perfusion acquisitions are available on all modern 64 slice scanners and has been shown to accurately quantify regions of contrast extravasation (Aviv et al., 2009). A biphasic CT Perfusion (CTP) protocol accurately quantifies regions of increased blood-brain barrier (BBB) permeability in acute ischemic stroke (AIS) and more recently in ICH by measuring CTP-PS (Aviv et al., 2009). Biphasic perfusion protocol use allows for simultaneous measurement of perfusion and permeability while reducing the radiation exposure to the patient. CTP-PS is the unidirectional rate of contrast extravasation from the intravascular to the extravascular space through a disrupted BBB (St Lawrence and Lee, 1998; Konstas et al., 2009a,b). Extravasation of contrast material leads to prolonged enhancement of the tissue beyond the intravascular (first) phase which can only be properly characterized by a two-phase CTP study. The CTP protocol includes an initial $45 \mathrm{~s}$ phase with continuous scanning at 1 rotation/s followed by 7 acquisitions $15 \mathrm{~s}$ apart for a total scan time of $\sim 2$ min (Aviv et al., 2009; Konstas et al., 2009a). The prolonged scan time circumvents the need for early or late CTA timing and more importantly allows accurate identification and quantification of the differential rates of contrast extravasation over time. This provides significant advantages over CTA/PCT studies which represent single arbitrarily timed snapshots of contrast leakage. Preliminary work indicates that differential rates of contrast extravasation account for the differential appearance of contrast leakage patterns which may be quantified with CTP-PS (D'Esterre et al., 2011). The differential rates of contrast extravasation may have significant implications in patient selection for hemostatic therapy and response to such therapy. Disadvantages of such CTP acquisitions include the inability to extract meaningful CTA data due to thick slices ( $5 \mathrm{~mm})$, limited spatial coverage $(\sim 4 \mathrm{~cm})$ and the need for a separate CTA acquisition for vascular assessment. Figure 6 demonstrates the formation and evolution of a CT Perfusion Spot Sign.

\section{INTRAVENOUS RECOMBINANT FACTOR VII(a (rFVIIA)}

Hemostatic therapy with intravenous recombinant factor VIIa (rFVIIa) within $4 \mathrm{~h}$ of ICH onset has been proven to significantly reduce hematoma growth in phase IIb $(n=399)$ and phase III 


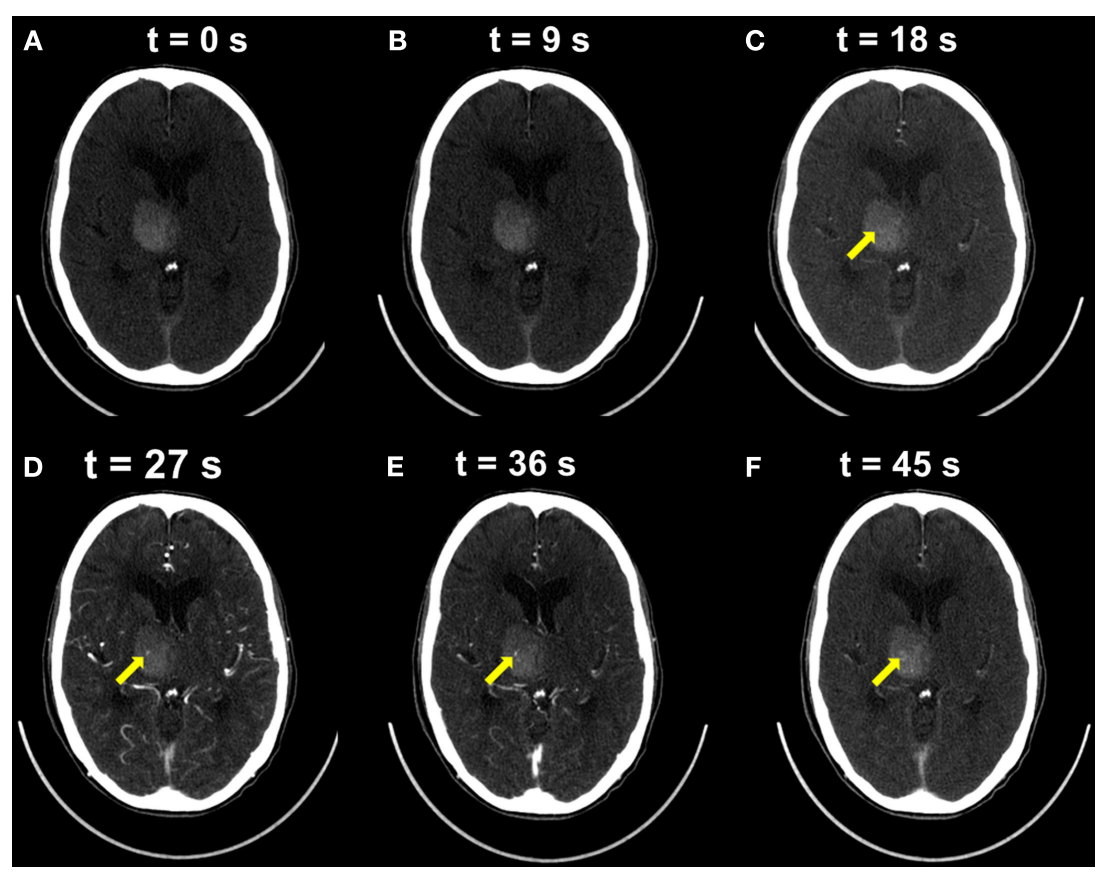

FIGURE 6 | The dynamic evolution of a CT Perfusion Spot Sign. A 86-year old female patient presenting within 105 min of symptom onset. Individual frames extracted from a dynamic CT perfusion study are presented. (A,B) No contrast enhancement is seen within the first $9 \mathrm{~s}$. (C,D) At $18 \mathrm{~s}$ early contrast is seen within a CT Spot Sign, peaking at $36 \mathrm{~s}$ (E) Dissipation of contrast material is seen on delayed image at $36 \mathrm{~s}$ (F) $(n=841)$ trials (Mayer, 2005; Mayer et al., 2005, 2008). Clinical efficacy has yet to be proven. Despite encouraging results in the phase IIb trial where rFVIIa reduced mortality rates and resulted in better functional outcomes, no significant differences in 90 day mortality or 90 day functional outcome were seen in the phase III trial. This may in part relate to the unselected nature of patients included. In particular, the majority of patients presenting with ICH do not have substantial early hematoma growth and would not benefit from hemostatic therapy (Mayer et al., 2009). Patients with larger hematomas are also predisposed to poorer outcomes independent of hematoma expansion. Stratification of patients based on the presence of a CTA Spot Sign and active extravasation may have impacted the outcome of the trial. Additional risk of cerebral infarction or myocardial ischemia conferred by factor VIIa underscores the limitations of its widespread clinical use (Mayer et al., 2008). A post hoc analysis restricted to patients treated within $2.5 \mathrm{~h}$ from symptom onset revealed that patients treated with $\mathrm{rFVII}$ had better outcomes (Mayer et al., 2009). This result underscores the importance of early imaging and reinforces the importance of early pathophysiological processes in hematoma expansion. Based on the robustness of the Spot Sign as an early surrogate of hematoma expansion in several studies (Wada et al., 2007; Kim et al., 2008; Delgado Almandoz et al., 2009), it is now being evaluated as a target for selecting patients for rFVIIa in two prospective studies (Spot Sign for Predicting \& Treating ICH Growth "STOPIT" Study and the Spot Sign Selection of Intracerebral Hemorrhage to Guide Hemostatic Therapy "SPOTLIGHT" Study). A recent prospective, international study, validating the utility of the Spot Sign for hematoma growth, supports the continued investigation of Spot Sign stratification for haemostatic treatment (Demchuk et al., 2012).

\section{CEREBRAL AMYLOID ANGIOPATHY}

ICH is considered primary in $78-88 \%$ of cases often attributed to hypertensive vasculopathy and CAA (Broderick et al., 1999). CAA accounts for the majority of primary lobar ICH in the elderly (Vinters and Gilbert, 1983; O'Donnell et al., 2000; Walker et al., 2004) and is seen in $40-60 \%$ of brains in patients older than 70 (Gilbert and Vinters, 1983; Vinters and Gilbert, 1983). A recent systemic review of amyloid angiopathy found an association between CAA and specifically lobar ICH, identifying CAA as a possible cause of lobar ICH (Samarasekera et al., 2012). Determination of ICH pathophysiology and etiology has been facilitated by the MRI detection of microbleeds on sequences susceptible to blood products (Offenbacher et al., 1996; Fazekas et al., 1999; Roob et al., 2000; Koennecke, 2006; Viswanathan and Chabriat, 2006). Fazekas first showed the association between MRI detected microbleeds and focal hemosiderin deposition (Fazekas et al., 1999). These findings, suggest that microbleeds may be considered as imaging surrogates of prior chronic, subclinical, hemorrhagic episodes from bleedingprone vessels affected by moderate to severe lipohyalinosis and/or amyloid deposits (Fazekas et al., 1999; Tanaka et al., 1999). Several studies have reported a correlation between microbleed number as predictor of future ICH occurrence and pattern (Fan et al., 2003; Greenberg et al., 2004; Soo et al., 2008). Amyloid deposition and chronic hypertension histopathologically demonstrate vessel wall thickening increasing with disease duration and severity (Fisher, 1971; Okoye and Watanabe, 1982; Mandybur, 1986). 
The mural changes occurring in leptomeningeal vessels, cortical arteries, arterioles and capillaries, are present in both CAA and chronic hypertension (Fisher, 1971). Both CAA and chronic hypertension are characterized radiologically by the presence of microbleed deposition. Microbleeds represent chronic, rather than acute, leakage of blood products and are indicative of underlying mural dysfunction (Fazekas et al., 1999; Tanaka et al., 1999). Cerebral amyloid initially deposits within the vessel wall without lumen narrowing (Mandybur, 1986). Progressive concentric intimal proliferation causes wall thickening and lumen reduction (Vonsattel et al., 1991). It is plausible to suggest that the same mural characteristics producing microbleeds may also impact upon vessel contractility and therefore bleeding rate, hematoma growth and Spot Sign frequency.

The degree of wall thickening and mural dysfunction may be implied by the number of microbleeds. This may have important implications for the type and incidence of future hemorrhage (Greenberg et al., 2009). Currently definite diagnosis of CAA can only be determined using pathology. A set of validated criteria, the Boston criteria, allows for radiographic diagnosis of probable CAA based upon number of microbleeds and location (Knudsen et al., 2001). Although these criteria are reported as relatively specific for CAA-related hemorrhage they have only been validated on 13 autopsy specimens (Groger and Marmarou, 1990). Nevertheless, based on the number of gradient recalled echo (GRE)MRI detected microbleeds, Greenberg hypothesized that patients presenting with acute ICH can be divided into micro- or macrobleeders (Greenberg et al., 2009). Microbleeders present with multiple small microbleeds and are histopathologically characterized by wall thickening in association with amyloid deposition. This observation is consistent with several studies demonstrating that extensive mural amyloid deposition is frequently associated with wall thickening and multiple subclinical microbleeds (Fisher, 1971; Okoye and Watanabe, 1982; Mandybur, 1986; Vonsattel et al., 1991; Fazekas et al., 1999; Tanaka et al., 1999; Goldstein et al., 2007). In contrast, macrobleeders demonstrate few prior microbleeds and are characterized histopathologically by vessel wall thinning.

Considering the increased mural thickening with increased disease severity in CAA and chronic hypertension (Okoye and Watanabe, 1982; Vinters and Gilbert, 1983; Mandybur, 1986; Vinters, 1987; Vonsattel et al., 1991) and the reported mural differences between micro- and macrobleeders (Greenberg et al., 2009), we recently proposed and confirmed that patients exhibiting MRI microbleeds as surrogates of probable CAA were less likely to manifest a CTA Spot Sign at acute ICH presentation (Figures 7,8). In a retrospective study of 59 patients presenting within $6 \mathrm{~h}$ of primary ICH onset undergoing CTA and MRI, Spot Sign presence was documented blinded to MRI. Hematoma expansion was defined as growth of more than $6 \mathrm{~mL}$ or $30 \%$ enlargement. Patients were dichotomized using the Boston criteria on GRE-MRI into probable and negative CAA (Evans et al., 2010). Basal ganglia, thalamic, and brainstem microbleed location were interpreted as chronic hypertensive pattern. Univariate logistic regression and ordinal logistic regression analysis identified significant predictive factors between Spot Sign positive and negative patients, or microbleed pattern. Spot Sign was seen in 42,22 , and $0 \%$ of CAA negative $(n=36)$, chronic hypertensive $(n=9)$, and CAA positive $(n=14)$ patients respectively $(p=0.01)$. Additionally, Spot Sign positive macrobleeders were less likely to have multiple microbleeds (mean $\pm \mathrm{SD}$; $0.53 \pm 0.8)$ than Spot Sign negative patients $(8.4 \pm 14 ; p=0.01)$. CAA negative patients had higher baseline NIHSS $(p=0.039)$, larger follow up hematoma volume $(p=0.02)$ and poorer Rankin score $(p=0.049)$ than chronic hypertensive or CAA positive patients. After age adjustment, Spot Sign positive $(p=0.023)$, Age related white matter change $(p=0.041)$, number of microbleeds $(p<0.0001)$, and modified Rankin score $(p=0.027)$ remained significantly different between groups. These results suggest that a probable CAA designation using MRI microbleed presence as a surrogate may be somewhat protective of rapid ICH expansion as characterized by the Spot Sign.

\section{AMYLOID IMAGING}

With the recent development of novel amyloid binding agents, the unique opportunity to visualize CAA in vivo is available. Investigation with an amyloid binding agent may strengthen the hypothesis that CAA deposition is somewhat protective of CTA Spot Sign-associated macrobleeds.

$N$-methyl-[(11)C]2-(4'-methylaminophenyl)-6-hydroxybenzothiazole (or [(11)C]PIB for "Pittsburgh Compound-B") uptake is well described in Alzheimer's disease (AD). Mintun et al. (2006) showed increased binding potential values for 11C-PIB in 9 of 10 patients with $\mathrm{AD}$. Little work has been done in the context of CAA and vascular amyloid imaging. Johnson and Ly both demonstrated that non-demented CAA patients showed intermediate 11C-PIB uptake compared to Alzheimer's and normal control patients (Johnson et al., 2007; Ly et al., 2010). The distribution of increased uptake was higher within the occipital lobes compared to both groups and consistent with CAA predilection for these lobes. Similarly, Remes demonstrated increased striatal, posterior cingulate and to a lesser extent putamen uptake compared to controls in two patients with autosomal dominant CAA related to APP locus duplication (Remes et al., 2008). The pattern of uptake although different from that seen in $\mathrm{AD}$ has been described in patients with Presenilin 1 gene mutations (Klunk et al., 2007). Pathologically, 2 members of the same family demonstrated both vessel wall and plaque Aßaccumulation. These observations, together with that of others confirm that both vascular CAA and $\mathrm{AD}$ plaque uptake may coexist in the same patient (Bacskai et al., 2003; Silva et al., 2005; Johnson et al., 2007; Klunk et al., 2007; Lockhart et al., 2007; Remes et al., 2008; Ly et al., 2010). Because of uptake in both locations, exclusion of underlying dementia or mild cognitive impairment is important. Further, limited imaging studies have to date considered the potential influence of the apolipoprotein $\mathrm{E}$ (ApoE) $-\epsilon$ 4 allele on the pattern of amyloid binding (Lockhart et al., 2007; Rowe et al., 2007). ApoE genotyping is important because ApoE $\in 4$ is linked with earlier dementia onset, more rapid cognitive decline, and a more pronounced accumulation of both senile plaques and CAA (Berg et al., 1998; Attems, 2005).

Very limited comparative MRI/radio-isotope studies are available in the context of CAA. In eight patients diagnosed with probable CAA based on Boston criteria on GRE MRI, seven demonstrated increased 11C-PIB uptake (88\%; Ly et al., 2010). The single patient without uptake had an unusual superficial 


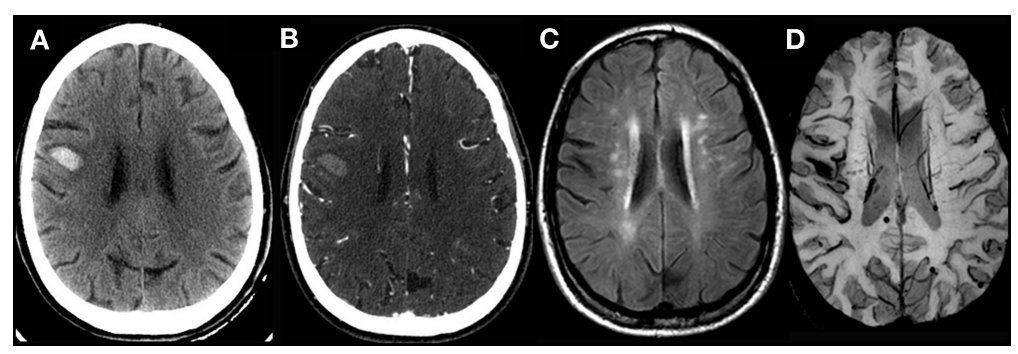

FIGURE 7 | A 65-year old male patient presenting with lobar hemorrhage. (A) Axial non-contrast CT demonstrates acute right frontal hematoma. (B) No Spot Sign is present on CTA raw images. (C) Extensive white matter changes are seen on fluid attenuated inversion recovery (FLAIR) MRI. (D) Multiple susceptibility foci are present on echoplanar-gradient echo MRI sequence fulfilling the Boston criteria for probable CAA.

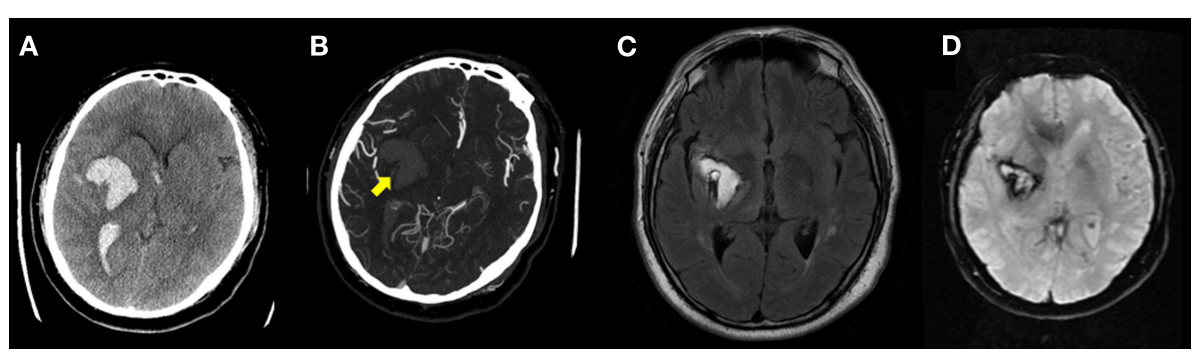

FIGURE 8 | A 44-year old male patient presenting within $78 \mathrm{~min}$ of symptom onset. (A) Axial non-contrast CT demonstrates a right basal ganglia intracerebral hemorrhage. (B) Spot Sign present on CTA source images. (C) Right basal ganglia hematoma visualized on fluid attenuated inversion recovery (FLAIR) MRI 6 weeks post ictus. (D) No microhemorrhage is seen on gradient echo MRI sequence consistent with a CAA negative status according to the Boston criteria. unilateral distribution of microbleeds atypical for a probable CAA diagnosis. A more recent study examined 11C-PIB uptake in a 42-year old man with early manifestations of Iowa-type hereditary CAA, characterized by little or no plaque deposits of fibrillar $\beta$-amyloid. Elevated 11C-PIB uptake within the occipital poles in the absence of microhemorrhages provided compelling evidence that CAA deposition may precede the radiographic evidence of vascular disease (Greenberg et al., 2008). In a study of 16 patients undergoing MRI and 11C-PIB imaging, 11C-PIB retention was increased at microbleed sites compared to simulated control lesions $(p=0.002)$ and declined with increasing distance from the microbleed ( $p<0.0001$; Dierksen et al., 2010). To exclude the possibility that 11C-PIB directly binds to cerebral microbleeds, Prussian blue and 11C-PIB was used to stain formalin-fixed brain tissue from three patients with definite CAA-related hemorrhages and three with hemorrhagic lesions from causes other than CAA. The locations of Prussian blue-positive microbleeds and 11C-PIB fluorescence were compared in adjacent sections. 11C-PIB showed no association with any of the hemorrhagic lesions. These findings suggest that microbleeds occur preferentially in local regions of concentrated amyloid.

Despite encouraging early results of amyloid binding, the short half-life $(20 \mathrm{~min})$ of the $11 \mathrm{C}$ isotope may limit the utility of $11 \mathrm{C}$ PIB as a tool for community based diagnostic screening and therapeutic evaluation. In contrast, Florpiramine F18 (Florbetapir) is a novel amyloid binding agent (Zhang, 2005; Zhang et al., 2007 ) labeled with $18 \mathrm{~F}$ which has a radioactive half-life of $110 \mathrm{~min}$, significantly simplifying its availability. Regional preparation and shipping of doses is possible, thereby reducing the cost and increasing the number of potential imaging centers. Studies conducted to date suggest that Florbetapir may label amyloid plaques in a manner similar to $11 \mathrm{C}-\mathrm{PIB}$, and may have the potential to serve as an agent for in vivo imaging of $\mathrm{A} \beta$ pathology in humans with AD. A comparison of the Florbetapir-PET semi-quantitative visual evaluation (0-4 rating scale) with the quantitative measurements of cortical amyloid burden using immunohistochemistry showed a statistically significant (Spearman's rho $=0.78$; $p<0.0001,95 \%$ CI, 0.58-0.89) correlation. In addition, strong correlations between Florbetapir-PET measures of $\beta$-amyloid and neuropathology measures of $\beta$-amyloid at autopsy were observed $(p<0.0001)$ across all the different methods of evaluating the PET images (qualitative and semi-quantitative visual ratings and quantitative SUVR) and the different methods of quantifying $\beta$-amyloid at autopsy (quantification of $A \beta$ and neuritic plaque density by silver staining) as well as in different brain regions (cortical average and six individual cortical regions).

Florbetapir exhibits high-affinity, specific binding to amyloid plaques with a $\mathrm{Kd}$ of $3.1 \mathrm{nM}$. In vitro autoradiography studies further confirm that when applied at tracer concentrations Florbetapir labels $A \beta$ amyloid plaques in sections from patients with pathologically confirmed AD. The non-radioactive version of Florbetapir can be prepared at high concentrations and shows very low to no affinity for all other central nervous system and cardiovascular receptors tested, including the hERG potassium channel 
binding site. Test-retest variance of Florbetapir-PET imaging has been demonstrated to be low (less than 5\%) in both AD patients and cognitively healthy controls. To date however, no specific work has been performed with this agent in CAA.

\section{ROLE OF APOE GENOTYPE IN CAA-RELATED HEMORRHAGE}

Previous studies have suggested that whereas ApoE $\in 4$ is associated with increased Aßdeposition in cerebral vasculature (Schmechel et al., 1993), ApoE $\in 2$ predisposes to increased hemorrhage in CAA (Nicoll et al., 1997). Hemorrhage may also occur at an earlier age in ApoE $\in 2$ carriers (Nicoll et al., 1996; Greenberg et al., 1998). Although the pathophysiology of hemorrhagic predisposition in ApoE $\in 2$ patients is unknown, increased fibrinoid necrosis (McCarron et al., 1999), and a combination of vessel wall splitting and paravascular hemorrhage (Greenberg et al., 1998) have been described. ApoE $\in 2$ allele was also recently found to interact with a number of clinical risk factors including antiplatelets, anticoagulants, hypertension, and minor trauma predisposing to a higher incidence of lobar hemorrhage. In a prospective study evaluating the interaction between ApoE genotype and risk of ICH in nearly 6000 patients, only patients with at least one $\in 2$ allele were significantly associated with ICH [Adjusted Hazard ratio (HR) 2.05; 95\% CI 1.26-2.26] compared to HR1.38 (95\% CI $0.86-2.21$ ) for patients with at least one $\in 4$ allele (Tzourio et al., 2008). Although APOE genotype does not appear sensitive or specific enough as an isolated variable to diagnose CAA in

\section{REFERENCES}

Anderson, C. S., Huang, Y., Wang, J. G., Arima, H., Neal, B., Peng, B., Heeley, E., Skulina, C., Parsons, M. W., Kim, J. S., Tao, Q. L., Li, Y. C., Jiang, J. D., Tai, L. W., Zhang, J. L., $\mathrm{Xu}$, E., Cheng, Y., Heritier, S., Morgenstern, L. B., Chalmers, J., and INTERACT Investigators. (2008). Intensive blood pressure reduction in acute cerebral haemorrhage trial (INTERACT): a randomised pilot trial. Lancet Neurol. 7, 391-399.

Attems, J. (2005). Sporadic cerebral amyloid angiopathy: pathology, clinical implications, and possible pathomechanisms. Acta Neuropathol. 110, 345-359.

Aviv, R. I., d'Esterre, C. D., Murphy, B. D., Hopyan, J. J., Buck, B., Mallia, G., Li, V., Zhang, L., Symons, S. P., and Lee, T. Y. (2009). Hemorrhagic transformation of ischemic stroke: prediction with CT perfusion. Radiology 250, 867-877.

Aviv, R. I., Aviv, R. I., Gladstone, D., Goldstein, J., Flaherty, M., Broderick, J., Demchuk, A., and Spot Sign for Predicting and Treating ICH Growth and Spot Sign Selection of ICH to Guide Hemostatic Therapy Investigators. (2008). Contrast extravasation predicts hematoma growth: where to now? AJNR Am. J. Neuroradiol. 29, E80.
Bacskai, B. J., Hickey, G. A., Skoch, J., Kajdasz, S. T., Wang, Y., Huang, G. F., Mathis, C. A., Klunk, W. E., and Hyman, B. T. (2003). Fourdimensional multiphoton imaging of brain entry, amyloid binding, and clearance of an amyloid-beta ligand in transgenic mice. Proc. Natl. Acad. Sci. U.S.A. 100, 12462-12467.

Becker, K. J., Baxter, A. B., Bybee, H. M., Tirschwell, D. L., Abouelsaad, T., and Cohen, W. A. (1999). Extravasation of radiographic contrast is an independent predictor of death in primary intracerebral hemorrhage. Stroke 30, 2025-2032.

Berg, L., McKeel, D. W. Jr., Miller, J. P., Storandt, M., Rubin, E. H., Morris, J. C., Baty, J., Coats, M., Norton, J., Goate, A. M., Price, J. L., Gearing, M., Mirra, S. S., and Saunders, A. M. (1998). Clinicopathologic studies in cognitively healthy aging and tologic markers to dementia severity, age, sex, and apolipoprotein E genotype. Arch. Neurol. 55, 326-335.

Broderick, J., Connolly, S., Feldmann, E., Hanley, D., Kase, C., Krieger, D., Mayberg, M., Morgenstern, L., Ogilvy, C. S., Vespa, P., Zuccarello, M., American Heart Association/American Stroke Association Stroke Council, American Heart Association/American Stroke Alzheimer's disease: relation of his-

individual patients, the incidence of $\in 2$ or $\in 4$ positivity is reported as 18-20 and 17-26\% in imaging and pathological studies (Greenberg et al., 1995, 1998; Nicoll et al., 1996; Premkumar et al., 1996). The above data however suggests that in the appropriate imaging setting of probable CAA, ApoE $\in 2$, or $\in 4$ genotypes may confer additional risk for CAA presence and progression and may provide valuable additional information when stratifying risk. The interplay between microbleeding, CAA, and CTA Spot Sign, as well as APOE genotype may be crucial in developing a risk model for ICH and expansion. Finally, CAA-specific agents also provide imaging surrogates for the assessment of secondary preventive therapy efficacy.

In conclusion, imaging remains at the forefront of understanding acute ICH formation and hematoma progression. An early surrogate marker of hematoma expansion, the CTA Spot Sign, is being prospectively evaluated as a potential target for rVIIa therapy. Modern CT protocols now facilitate direct quantification of hematoma expansion rates and these measures correlate with the different morphological patterns seen on CTA and CECT. It is likely that future treatment algorithms will be determined by absolute expansion rates rather than morphological features alone. CAA remains a central pathophysiology in primary ICH. In vivo imaging of CAA provides a unique opportunity of understanding the complex relationship between amyloid load, risk of hematoma formation, the CTA Spot Sign and genetic factors.

Association High Blood Pressure Research Council, and Quality of Care, and Outcomes in Research Interdisciplinary Working Group. (2007). Guidelines for the management of spontaneous intracerebral hemorrhage in adults: 2007 update: a guideline from the American Heart Association/American Stroke Association Stroke Council, High Blood Pressure Research Council, and the Quality of Care and Outcomes in Research Interdisciplinary Working Group. Stroke 38, 2001-2023.

Broderick, J. P., Adams, H. P. Jr., Barsan, W., Feinberg, W., Feldmann, E., Grotta, J., Kase, C., Krieger, D., Mayberg, M., Tilley, B., Zabramski, J. M., and Zuccarello, M. (1999). Guidelines for the management of spontaneous intracerebral hemorrhage: a statement for healthcare professionals from a special writing group of the Stroke Council, American Heart Association. Stroke 30, 905-915.

Broderick, J. P., Brott, T. G., Duldner, J. E., Tomsick, T., and Huster, G. (1993). Volume of intracerebral hemorrhage. A powerful and easyto-use predictor of 30-day mortality. Stroke 24, 987-993.

Brott, T., Broderick, J., Kothari, R., Barsan, W., Tomsick, T., Sauerbeck, L., Spilker, J., Duldner, J., and Khoury, J. (1997). Early hemorrhage growth in patients with intracerebral hemorrhage. Stroke 28, 1-5.

Chakraborty, S., Blacquiere, D., Lum, C., and Stotts, G. (2010). Dynamic nature of the CT angiographic “spot sign.” Br. J. Radiol. 83, e216-e219.

Chalela, J. A., Kidwell, C. S., Nentwich, L. M., Luby, M., Butman, J. A., Demchuk, A. M., Hill, M. D., Patronas, N., Latour, L., and Warach, S. (2007). Magnetic resonance imaging and computed tomography in emergency assessment of patients with suspected acute stroke: a prospective comparison. Lancet 369, 293-298.

Charcot, C. M., and Bouchard, C. (1868). Nouvelle recherches sur la pathogenie de l'hemorrhagie cerebrale. Arch. Physiol. Norm. Pathol. 1868, 643-645.

Cheung, R. T. (1998). Predictors of hematoma growth? Stroke 29, 2442-2443.

Davis, S. M., Broderick, J., Hennerici, M., Brun, N. C., Diringer, M. N., Mayer, S. A., Begtrup, K., Steiner, T., and Recombinant Activated Factor VII Intracerebral Hemorrhage Trial Investigators. (2006). Hematoma growth is a determinant of mortality and poor outcome after intracerebral hemorrhage. Neurology 66, 1175-1181. 
Delgado Almandoz, J. E., Yoo, A. J., Stone, M. J., Schaefer, P. W., Goldstein, J. N., Rosand, J., Oleinik, A., Lev, M. H., Gonzalez, R. G., and Romero, J. M. (2009). Systematic characterization of the computed tomography angiography spot sign in primary intracerebral hemorrhage identifies patients at highest risk for hematoma expansion: the spot sign score. Stroke 40, 2994-3000.

Delgado Almandoz, J. E., Yoo, A. J., Stone, M. J., Schaefer, P. W., Oleinik, A., Brouwers, H. B., Goldstein, J. N., Rosand, J., Lev, M. H., Gonzalez, R. G., and Romero, J. M. (2010). The spot sign score in primary intracerebral hemorrhage identifies patients at highest risk of in-hospital mortality and poor outcome among survivors. Stroke 41, 54-60.

Demchuk, A. M., Dowlatshahi, D., Rodriguez-Luna, D., Molina, C. A., Blas, Y. S., Dzialowski, I., Kobayashi, A., Boulanger, J. M., Lum, C., Gubitz, G., Padma, V., Roy, J., Kase, C. S., Kosior, J., Bhatia, R., Tymchuk, S., Subramaniam, S., Gladstone, D. J., Hill, M. D., Aviv, R. I., and PREDICT/Sunnybrook ICH CTA study group. (2012). Prediction of haematoma growth and outcome in patients with intracerebral haemorrhage using the CT-angiography spot sign (PREDICT): a prospective observational study. Lancet Neurol. $11,307-314$

D'Esterre, C. D., Chia, T. L., Jairath, A., Lee, T. Y., Symons, S. P., and Aviv, R. I. (2011). Early rate of contrast extravasation in patients with intracerebral hemorrhage. AJNR Am. J. Neuroradiol. 32, 1879-1884.

Dierksen, G. A., Skehan, M. E., Khan, M. A., Jeng, J., Nandigam, R. N., Becker, J. A., Kumar, A., Neal, K. L., Betensky, R. A., Frosch, M. P., Rosand, J., Johnson, K. A., Viswanathan, A., Salat, D. H., Greenberg, S. M. (2010). Spatial relation between microbleeds and amyloid deposits in amyloid angiopathy. Ann. Neurol. 68, 545-548.

Dowlatshahi, D., Demchuk, A. M., Flaherty, M. L., Ali, M., Lyden, P. L., Smith, E. E., and VISTA Collaboration. (2011). Defining hematoma expansion in intracerebral hemorrhage: relationship with patient outcomes. Neurology 76, 1238-1244.

Ederies, A., Demchuk, A., Chia, T., Gladstone, D. J., Dowlatshahi, D., Bendavit, G., Wong, K., Symons, S. P., and Aviv, R. I. (2009). Postcontrast CT extravasation is associated with hematoma expansion in CTA spot negative patients. Stroke 40, 1672-1676.

Evans, A., Demchuk, A., Symons, S. P., Dowlatshahi, D., Gladstone, D. J., Zhang, L., Fox, A. J., and Aviv, R. I. (2010). The spot sign is more common in the absence of multiple prior microbleeds. Stroke 41, 2210-2217.

Fan, Y. H., Zhang, L., Lam, W. W., Mok, V. C., and Wong, K. S. (2003). Cerebral microbleeds as a risk factor for subsequent intracerebral hemorrhages among patients with acute ischemic stroke. Stroke 34, 2459-2462.

Fazekas, F., Kleinert, R., Roob, G., Kleinert, G., Kapeller, P., Schmidt, R., and Hartung, H. P. (1999). Histopathologic analysis of foci of signal loss on gradient-echo $\mathrm{T} 2 *$-weighted MR images in patients with spontaneous intracerebral hemorrhage: evidence of microangiopathy-related microbleeds. AJNR Am. J. Neuroradiol. 20, 637-642.

Fiebach, J. B., Schellinger, P. D., Gass, A., Kucinski, T., Siebler, M., Villringer, A., Olkers, P., Hirsch, J. G., Heiland, S., Wilde, P., Jansen, O., Röther, J., Hacke, W., Sartor, K., and Kompetenznetzwerk Schlaganfall B5. (2004). Stroke magnetic resonance imaging is accurate in hyperacute intracerebral hemorrhage: a multicenter study on the validity of stroke imaging. Stroke 35, 502-506.

Fisher, C. M. (1971). Pathological observations in hypertensive cerebral hemorrhage. J. Neuropathol. Exp. Neurol. 30, 536-550.

Flaherty, M. L., Haverbusch, M., Sekar, P., Kissela, B., Kleindorfer, D., Moomaw, C. J., Sauerbeck, D. L., Schneider, A., Broderick, J. P., and Woo, D. (2006). Long-term mortality after intracerebral hemorrhage. Neurology 66, 1182-1186.

Flaherty, M. L., Kissela, B., Woo, D., Kleindorfer, D., Alwell, K., Sekar, P., Moomaw, C. J., Haverbusch, M., and Broderick, J. P. (2007). The increasing incidence of anticoagulant-associated intracerebral hemorrhage. Neurology 68, 116-121.

Fogelholm, R., Avikainen, S., and Murros, K. (1997). Prognostic value and determinants of first-day mean arterial pressure in spontaneous supratentorial intracerebral hemorrhage. Stroke 28, 1396-1400.

Fujii, Y., Takeuchi, S., Sasaki, O., Minakawa, T., and Tanaka, R. (1998). Multivariate analysis of predictors of hematoma enlargement in spontaneous intracerebral hemorrhage. Stroke 29, 1160-1166.
Gazzola, S., Aviv, R. I., Gladstone, D. J., Mallia, G., Li, V., Fox, A. J., and Symons, S. P. (2008). Vascular and nonvascular mimics of the CT angiography "spot sign" in patients with secondary intracerebral hemorrhage. Stroke 39, 1177-1183.

Gilbert, J. J., and Vinters, H. V. (1983). Cerebral amyloid angiopathy: incidence and complications in the aging brain. I. Cerebral hemorrhage. Stroke 14, 915-923.

Goldstein, J. N., Fazen, L. E., Snider, R., Schwab, K., Greenberg, S. M. Smith, E. E., Lev, M. H., and Rosand, J. (2007). Contrast extravasation on CT angiography predicts hematoma expansion in intracerebral hemorrhage. Neurology 68, 889-894.

Greenberg, S. M., Eng, J. A., Ning, M. Smith, E. E., Rosand, J. (2004). Hemorrhage burden predicts recurrent intracerebral hemorrhage after lobar hemorrhage. Stroke 35, 1415-1420.

Greenberg, S. M., Grabowski, T., Gurol, M. E., Skehan, M. E., Nandigam, R. N., Becker, J. A., Garcia-Alloza, M., Prada, C., Frosch, M. P., Rosand, J., Viswanathan, A., Smith, E. E., Johnson, K. A. (2008). Detection of isolated cerebrovascular beta-amyloid with Pittsburgh compound B. Ann. Neurol. 64, 587-591.

Greenberg, S. M., Nandigam, R. N., Delgado, P., Betensky, R. A., Rosand, J., Viswanathan, A., Frosch, M. P., and Smith, E. E. (2009). Microbleeds versus macrobleeds: evidence for distinct entities. Stroke 40, 2382-2386.

Greenberg, S. M., Rebeck, G. W., Vonsattel, J. P., Gomez-Isla, T., and Hyman, B. T. (1995). Apolipoprotein E epsilon 4 and cerebral hemorrhage associated with amyloid angiopathy. Ann. Neurol. 38, 254-259.

Greenberg, S. M., Vonsattel, J. P., Segal, A. Z., Chiu, R. I., Clatworthy, A. E., Liao, A., Hyman, B. T., and Rebeck, G. W. (1998). Association of apolipoprotein E epsilon2 and vasculopathy in cerebral amyloid angiopathy. Neurology 50, 961-965.

Groger, U., and Marmarou, A. (1990). "Importance of protein content in the edema fluid for the resolution of brain edema," in Advances in Neurology - Brain Edema: Pathogenesis, Imaging, and Therapy, ed. D. Long (New York: Raven Press), 215-218.

Hallevi, H., Abraham, A. T., Barreto, A. D., Grotta, J. C., and Savitz, S. I. (2010). The spot sign in intracerebral hemorrhage: the importance of looking for contrast extravasation. Cerebrovasc. Dis. 29, 217-220.

Johnson, K. A., Gregas, M., Becker, J. A., Kinnecom, C., Salat, D. H., Moran, E. K., Smith, E. E., Rosand, J., Rentz, D.
M., Klunk, W. E., Mathis, C. A., Price, J. C., Dekosky, S. T., Fischman, A. J., and Greenberg, S. M. (2007). Imaging of amyloid burden and distribution in cerebral amyloid angiopathy. Ann. Neurol. 62, 229-234.

Kazui, S., Minematsu, K., Yamamoto, H., Sawada, T., and Yamaguchi, T. (1997). Predisposing factors to enlargement of spontaneous intracerebral hematoma. Stroke 28, 2370-2375.

Kazui, S., Naritomi, H., Yamamoto, H., Sawada, T., and Yamaguchi, T. (1996). Enlargement of spontaneous intracerebral hemorrhage: incidence and time course. Stroke 27, 1783-1787.

Kim, J., Smith, A., Hemphill, J. C. III, Smith, W. S., Lu, Y., Dillon, W. P., and Wintermark, M. (2008). Contrast extravasation on CT predicts mortality in primary intracerebral hemorrhage. AJNR Am. J. Neuroradiol. 29, 520-525.

Klunk, W. E., Price, J. C., Mathis, C. A., Tsopelas, N. D., Lopresti, B. J., Ziolko, S. K., Bi, W., Hoge, J. A., Cohen, A. D., Ikonomovic, M. D., Saxton, J. A., Snitz, B. E., Pollen, D. A., Moonis, M., Lippa, C. F., Swearer, J. M., Johnson, K. A., Rentz, D. M., Fischman, A. J., Aizenstein, H. J., and DeKosky, S. T. (2007). Amyloid deposition begins in the striatum of presenilin-1 mutation carriers from two unrelated pedigrees. J. Neurosci. 27, 6174-6184.

Knudsen, K. A., Rosand, J., Karluk, D., and Greenberg, S. M. (2001). Clinical diagnosis of cerebral amyloid angiopathy: validation of the Boston criteria. Neurology 56, 537-539.

Kobayashi, S., Nakazawa, S., Yano, M., and Otsuka, T. (1985). Extravasation of contrast medium into blood clot in acute traumatic intraventricular hemorrhage. Neurol. Med. Chir. (Tokyo) 25, 32-35.

Koennecke, H.-C. (2006). Cerebral microbleeds on MRI. J. Neurol. 66, 165-171.

Komiyama, M., Yasui, T., Tamura, K., Nagata, Y., Fu, Y., and Yagura, H. (1995). Simultaneous bleeding from multiple lenticulostriate arteries in hypertensive intracerebral haemorrhage. Neuroradiology 37, 129-130.

Konstas, A. A., Goldmakher, G. V., Lee, T. Y., and Lev, M. H. (2009a). Theoretic basis and technical implementations of CT perfusion in acute ischemic stroke, part 2: technical implementations. AJNR Am. J. Neuroradiol. 30, 885-892.

Konstas, A. A., Goldmakher, G. V., Lee, T. Y., and Lev, M. H. (2009b). Theoretic basis and technical implementations 
of CT perfusion in acute ischemic stroke, part 1: theoretic basis. AJNR Am. J. Neuroradiol. 30, 662-668.

Kowada, M., Yamaguchi, K., Matsuoka, S., and Ito, Z. (1972). Extravasation of angiographic contrast material in hypertensive intracerebral hemorrhage. J. Neurosurg. 36, 471-473.

Leira, R., Dávalos, A., Silva, Y., GilPeralta, A., Tejada, J., Garcia, M., and Castillo, J. (2004). Early neurologic deterioration in intracerebral hemorrhage: predictors and associated factors. Neurology 63, 461-467.

Li, N., Wang, Y., Wang, W., Ma, L., Xue, J., Weissenborn, K., Dengler, R., Worthmann, H., Wang, D. Z., Gao, P., Liu, L., Wang, Y., and Zhao, X. (2011). Contrast extravasation on computed tomography angiography predicts clinical outcome in primary intracerebral hemorrhage: a prospective study of 139 cases. Stroke 42, 3441-3446.

Lockhart, A., Lamb, J. R., Osredkar, T., Sue, L. I., Joyce, J. N., Ye, L., Libri, V., Leppert, D., and Beach, T. G. (2007). $\mathrm{PIB}$ is a non-specific imaging marker of amyloid-beta (Abeta) peptiderelated cerebral amyloidosis. Brain 130(Pt 10), 2607-2615.

Lovelock, C. E., Molyneux, A. J., and Rothwell, P. M. (2007). Change in incidence and aetiology of intracerebral haemorrhage in Oxfordshire, UK, between 1981 and 2006: a population-based study. Lancet $\mathrm{Neu}$ rol. 6, 487-493.

Ly, J. V., Donnan, G. A., Villemagne, V. L., Zavala, J. A., Ma, H., O'Keefe, G., Gong, S. J., Gunawan, R. M., Saunder, T., Ackerman, U., TochonDanguy, H., Churilov, L., Phan, T. G., and Rowe, C. C. (2010). 11C-PIB binding is increased in patients with cerebral amyloid angiopathy-related hemorrhage. Neurology 74, 487-493.

Mandybur, T. I. (1986). Cerebral amyloid angiopathy: the vascular pathology and complications. J. Neuropathol. Exp. Neurol. 45, 79-90.

Mayer, S. A. (2005). Ultra-early hemostatic therapy for primary intracerebral hemorrhage: a review. Can. J. Neurol. Sci. 32(Suppl. 2), S31-S37.

Mayer, S. A., Brun, N. C., Begtrup, K., Broderick, J., Davis, S., Diringer, M. N., Skolnick, B. E., Steiner, T., and FAST Trial Investigators. (2008). Efficacy and safety of recombinant activated factor VII for acute intracerebral hemorrhage. N. Engl. J. Med. 358, 2127-2137.

Mayer, S. A., Brun, N. C., Begtrup, K., Broderick, J., Davis, S., Diringer, M. N., Skolnick, B. E., Steiner, T., Recombinant Activated Factor VII Intracerebral Hemorrhage Trial
Investigators. (2005). Recombinant activated factor VII for acute intracerebral hemorrhage. N. Engl. J. Med. 352, 777-785.

Mayer, S. A., Davis, S. M., Skolnick, B. E., Brun, N. C., Begtrup, K., Broderick, J. P., Diringer, M. N., Steiner, T., and FAST trial investigators. (2009). Can a subset of intracerebral hemorrhage patients benefit from hemostatic therapy with recombinant activated factor VII? Stroke 40, 833-840.

Mayo, N. E., Nadeau, L., Daskalopoulou, S. S., and Côté, R. (2007). The evolution of stroke in Quebec: a 15-year perspective. Neurology 68, 1122-1127.

McCarron, M. O., Nicoll, J. A., Stewart, J., Ironside, J. W., Mann, D. M., Love, S., Graham, D. I., and Dewar, D. (1999). The apolipoprotein E epsilon2 allele and the pathological features in cerebral amyloid angiopathy-related hemorrhage. J. Neuropathol. Exp. Neurol. 58, 711-718.

Mintun, M. A., Larossa, G. N., Sheline, Y. I., Dence, C. S., Lee, S. Y., Mach, R. H., Klunk, W. E., Mathis, C. A., DeKosky, S. T., and Morris, J. C. (2006). [11C]PIB in a nondemented population: potential antecedent marker of Alzheimer disease. Neurology 67, 446-452.

Morgenstern, L. B., Hemphill, J. C. III, Anderson, C., Becker, K., Broderick, J. P., Connolly, E. S. Jr., Greenberg, S. M., Huang, J. N., MacDonald, R. L., Messé, S. R., Mitchell, P. H., Selim, M., Tamargo, R. J., American Heart Association Stroke Council, and Council on Cardiovascular Nursing. (2010). Guidelines for the management of spontaneous intracerebral hemorrhage: a guideline for healthcare professionals from the American Heart Association/American Stroke Association. Stroke 41, 2108-2129.

Nicoll, J. A., Burnett, C., Love, S., Graham, D. I., Dewar, D., Ironside, J. W., Stewart, J., and Vinters, H. V. (1997). High frequency of apolipoprotein E epsilon 2 allele in hemorrhage due to cerebral amyloid angiopathy. Ann. Neurol. 41, 716-721.

Nicoll, J. A., Burnett, C., Love, S., Graham, D. I., Ironside, J. W., and Vinters, H. V. (1996). High frequency of apolipoprotein E epsilon 2 in patients with cerebral hemorrhage due to cerebral amyloid angiopathy. Ann. Neurol. 39, 682-683.

Nilsson, O. G., Lindgren, A., Brandt, L., and Säveland, H. (2002). Prediction of death in patients with primary intracerebral hemorrhage: a prospective study of a defined population. J. Neurosurg. 97, 531-536.

O’Donnell, H. C., Rosand, J., Knudsen, K. A., Furie, K. L., Segal, A. Z., Chiu, R. I., Ikeda, D., and Greenberg, S. M. (2000). Apolipoprotein E genotype and the risk of recurrent lobar intracerebral hemorrhage. N. Engl. J. Med. 342, 240-245.

Offenbacher, H., Fazekas, F., Schmidt, R., Koch, M., Fazekas, G., and Kapeller, P. (1996). MR of cerebral abnormalities concomitant with primary intracerebral hematomas. AJNR Am. J. Neuroradiol. 17, 573-578.

Ohwaki, K., Yano, E., Nagashima, H., Hirata, M., Nakagomi, T., and Tamura, A. (2004). Blood pressure management in acute intracerebral hemorrhage: relationship between elevated blood pressure and hematoma enlargement. Stroke 35 1364-1367.

Okoye, M. I., and Watanabe, I. (1982) Ultrastructural features of cerebral amyloid angiopathy. Hum. Pathol. 13, 1127-1132.

Premkumar, D. R., Cohen, D. L., Hedera, P., Friedland, R. P., and Kalaria, R. N. (1996). Apolipoprotein E-epsilon4 alleles in cerebral amyloid angiopathy and cerebrovascular pathology associated with Alzheimer's disease. Am. J. Pathol. 148, 2083-2095.

Qureshi, A. I., Harris-Lane, P., Kirmani, J. F., Ahmed, S., Jacob, M., Zada, Y., and Divani, A. A. (2006). Treatment of acute hypertension in patients with intracerebral hemorrhage using American Heart Association guidelines. Crit. Care Med. 34 1975-1980.

Qureshi, A. I., Ling, G. S., Khan, J., Suri, M. F., Miskolczi, L., Guterman, L. R., and Hopkins, L. N. (2001). Quantitative analysis of injured, necrotic, and apoptotic cells in a new experimental model of intracerebral hemorrhage. Crit. Care Med. 29, 152-157.

Qureshi, A. I., Suri, M. F., Nasar, A. and Kirmani, J. F., Ezzeddine, M. A., Divani, A. A., and Giles, W. H. (2007). Changes in cost and outcome among US patients with stroke hospitalized in 1990 to 1991 and those hospitalized in 2000 to 2001. Stroke 38, 2180-2184.

Remes, A. M., Laru, L., Tuominen, H., Aalto, S., Kemppainen, N., Mononen, H., Någren, K., Parkkola, R., and Rinne, J. O. (2008). Carbon 11-labeled pittsburgh compound $\mathrm{B}$ positron emission tomographic amyloid imaging in patients with APP locus duplication. Arch. Neurol. 65, 540-544.
Roob, G., Lechner, A., Schmidt, R., Flooh, E., Hartung, H. P., and Fazekas, F. (2000). Frequency and location of microbleeds in patients with primary intracerebral hemorrhage. Stroke 31, 2665-2669.

Rowe, C. C., Ng, S., Ackermann, U., Gong, S. J., Pike, K., Savage, G., Cowie, T. F., Dickinson, K. L., Maruff, P., Darby, D., Smith, C., Woodward, M., Merory, J., TochonDanguy, H., O’Keefe, G., Klunk, W. E., Mathis, C. A., Price, J. C., Masters, C. L., and Villemagne, V. L. (2007). Imaging beta-amyloid burden in aging and dementia. Neurology 68, 1718-1725.

Samarasekera, N., Smith, C., and Al-Shahi Salman, R. (2012). The association between cerebral amyloid angiopathy and intracerebral haemorrhage: systematic review and meta-analysis. J. Neurol. Neurosurg. Psychiatr. 83, 275-281.

Schmechel, D. E., Saunders, A. M., Strittmatter, W. J., Crain, B. J., Hulette, C. M., Joo, S. H., PericakVance, M. A., Goldgaber, D., and Roses, A. D. (1993). Increased amyloid beta-peptide deposition in cerebral cortex as a consequence of apolipoprotein E genotype in lateonset Alzheimer disease. Proc. Natl. Acad. Sci. U.S.A. 90, 9649-9653.

Silva, Y., Leira, R., Tejada, J., Lainez, J. M., Castillo, J., Dávalos, A., and Stroke Project, Cerebrovascular Diseases Group of the Spanish Neurological Society. (2005). Molecular signatures of vascular injury are associated with early growth of intracerebral hemorrhage. Stroke 36, 86-91.

Soo, Y. O., Yang, S. R., Lam, W. W., Wong, A., Fan, Y. H., Leung, H. H., Chan, A.Y., Leung, C., Leung, T. W., and Wong, L. K. (2008). Risk versus benefit of anti-thrombotic therpay in ischaemic stroke patients with microbleeds. J. Neurol. 255, 1679-1686.

St Lawrence, K. S., and Lee, T. Y. (1998). An adiabatic approximation to the tissue homogeneity model for water exchange in the brain: I. theoretical derivation. J. Cereb. Blood Flow Metab. 18, 1365-1377.

Tanaka, A., Ueno, Y., Nakayama, Y., Takano, K., and Takebayashi, S. (1999). Small chronic hemorrhages and ischemic lesions in association with spontaneous intracerebral hematomas. Stroke 30, 5-1637.

Thompson, A. L., Kosior, J. C., Gladstone, D. J., Hopyan, J. J., Symons, S. P., Romero, F., Dzialowski, I., Roy, J., Demchuk, A. M., Aviv, R. I., and PREDICTS/Sunnybrook ICH 
CTA Study Group. (2009). Defining the CT angiography "spot sign" in primary intracerebral hemorrhage. Can. J. Neurol. Sci. 36, 456-461.

Tzourio, C., Arima, H., Harrap, S., Anderson, C., Godin, O., Woodward, M., Neal, B., Bousser, M. G., Chalmers, J., Cambien, F., and MacMahon, S. (2008). APOE genotype, ethnicity, and the risk of cerebral hemorrhage. Neurology 70, 1322-1328.

van Asch, C. J., Ja Luitse, M., Je Rinkel, G., van der Tweel, I., Algra, A., and Jm Klijn, C. (2010). Incidence, case fatality, and functional outcome of intracerebral haemorrhage over time, according to age, sex, and ethnic origin: a systematic review and meta-analysis. Lancet Neurol. 9 , 167-176.

Vinters, H. (1987). Cerebral amyloid angiopathy. A critical review. Stroke $18,311-324$.
Vinters, H. V., and Gilbert, J. J. (1983). Cerebral amyloid angiopathy: incidence and complications in the aging brain. II. The distribution of amyloid vascular changes. Stroke 14 , 924-928.

Viswanathan, A., and Chabriat, $\mathrm{H}$ (2006). Cerebral microhemorrhage. Stroke 37, 550-555.

Vonsattel, J. P., Myers, R. H., HedleyWhyte, E. T., Ropper, A. H., Bird, E. D., and Richardson, E. P. Jr. (1991). Cerebral amyloid angiopathy without and with cerebral hemorrhages: a comparative histological study. Ann. Neurol. 30, 637-649.

Wada, R., Aviv, R. I., Fox, A. J., Sahlas, D. J., Gladstone, D. J., Tomlinson, G., and Symons, S. P. (2007). CT angiography "spot sign" predicts hematoma expansion in acute intracerebral hemorrhage. Stroke 38, 1257-1262.
Walker, D. A., Broderick, D. F., Kotsenas, A. L., and Rubino, F. A. (2004). Routine use of gradient-echo MRI to screen for cerebral amyloid angiopathy in elderly patients. AJR Am. J. Roentgenol. 182, 1547-1550.

Yamaki, T., Yoshino, E., and Higuchi, T. (1983). Extravasation of contrast medium during both computed tomography and cerebral angiography. Surg. Neurol. 19, 247-250.

Zhang, W. (2005). F-18 stilbenes as PET imaging agents for detecting betaamyloid plaques in the brain. J. Med. Chem. 48, 5980-5988.

Zhang, W., Oya, S., Kung, M. P., Hou, C., Maier, D. L., and Kung, H. F. (2007) $18 \mathrm{~F}$-labeled styrylpyridines as PET agents for amyloid plaque imaging. Nucl. Med. Biol. 34, 89-97.

Conflict of Interest Statement: The authors declare that the research was conducted in the absence of any commercial or financial relationships that could be construed as a potential conflict of interest.

Received: 29 February 2012; paper pending published: 20 March 2012; accepted: 07 May 2012; published online: 25 May 2012.

Citation: Jakubovic R and Aviv RI (2012) Intracerebral hemorrhage: toward physiological imaging of hemorrhage risk in acute and chronic bleeding. Front. Neur. 3:86. doi: 10.3389/fneur.2012.00086

This article was submitted to Frontiers in Stroke, a specialty of Frontiers in Neurology.

Copyright (c) 2012 Jakubovic and Aviv. This is an open-access article distributed under the terms of the Creative Commons Attribution Non Commercial License, which permits non-commercial use, distribution, and reproduction in other forums, provided the original authors and source are credited. 